tion of the great arteries: management of hypoxemia after balloon atrial septostomy. Am J Cardiol 1981;47:299-306.

4 Allan LD, Leanage R, Wainwright $R$, Joseph MC, Tynan M. Balloon atrial septostomy MC, Tynan M. Balloon atrial septostomy
under two dimensional echocardiographic under two dimensional echocardio

5 Venables AW. Balloon atrial septostomy in complete transposition of great arteries in infancy. Br Heart J 1970;32:61-5.

These letters were shown to the authors, who reply as follows:

SIR,-We agree entirely with Dr Abinader's comments. Neither the use of ultrasound imaging nor the umbilical vein route are new techniques for the performance of an atrial septostomy and in our paper we did not intend to suggest that this was the case. The initial intention was to review our experience with the efficacy of ultrasound imaging. In most centres the umbilical route has not been used routinely in the past because of difficulty in catheter manipulation where a full catheterisation is necessary to establish the diagnosis. Catheterisation is now necessary only for the performance of a septostomy and the umbilical route is ideal for this. We thought it appropriate to add our experience of the use of the umbilical route pioneered by Abinader et al because we were aware that many centres still did not use it.

We referred in some detail to the different workers who have commented on the ultrasound technique, which has become popular only in recent years. The use of the umbilical vein technique has been known for over 20 years and indeed it was described in 1985 in a major textbook on paediatric cardiology to which we referred.' We thus considered it was not necessary to refer in detail to the initial reports on this, and we agree it would have been appropriate to quote the early paper on the subject.

We would like to take the opportunity of stating that we are no longer sure of the accuracy of the comment that the ultrasound image is of little value in the manipulation of the catheter. In a newborn the heart was only entered after the image had been used to ensure that the catheter was inserted with the bend aligned in a posterior and inferior direction and then, at the appropriate point as determined from the image, it was turned through a $180^{\circ}$ angle to pass through the ductus venosus and into the inferior vena cava and thence the heart.

Drs Kerkar and Dalvi question the validity of our supposition that a septostomy performed under ultrasound is as effective as one performed under fluoroscopy. Ours was a retrospective study and the size of the defect was not measured routinely. As their letter points out the "success" of a septostomy is difficult to define and there is more to it than simply the size of the defect. Because elective arterial switch procedures are performed within the first weeks of life data on long-term follow up can no longer be obtained. None of our patients required "emergency" surgery but in some prostaglandin therapy was continued or started after septostomy. The comment that "the size . . . showed the procedure was successful" was made on the basis of seeing a tear, a flapping septum, and an increase in the size of the defect. If the criticism is related to the use of ultrasound I cannot accept that there is any reason that the result could be different because the actual technique of pulling the catheter is no different with ultrasound or screening. We have not compared the results of using the umbilical and femoral routes but both have been accepted techniques for years. The facilities of a catheterisation laboratory are not needed for septostomy under ultrasound screening. In our paper we stated that for 10 months the ward side room was used when catheterisation facilities were unavailable; thereafter we have used the catheterisation laboratory routinely simply as a matter of convenience to the nursing staff; the $x$ ray imaging facilities are not used. Where necessary septostomy is undertaken in the ward, intensive therapy unit, or maternity hospital. The location is simply a matter of personal choice and hospital routine and again I cannot suppose that there is any reason that the result would be different for ultrasound and fluoroscopy.

I accept that in experienced hands the risk of mitral damage is almost negligible-but reports attest to the fact that damage does occur with fluoroscopy. I am unaware of this happening with ultrasound screening. In addition I accept that there should be little difference in the time of the procedure whether ultrasound or fluoroscopy is used. In the past there might have been a potential delay in obtaining the services of a radiographer or access to a catheterisation laboratory in an emergency, but this is now of less concern because the infant can be maintained on prostaglandins and the septostomy performed at a convenient time.

Thus I agree with some of Drs Kerkar and Dalvi's comments but I disagree with the conclusion to their letter. In our centre the simplicity and convenience of ultrasound quickly made it the technique of choice. A preference for ultrasound or fluoroscopy may simply be a matter of personal choice, experience with ultrasound, and the hospital facilities available. However, my colleagues and I firmly believe that it is correct to advocate ultrasound as a more convenient and better imaging technique than fluoroscopy. ALAN HOUSTON Royal Hospital for Sick Children, Yorkhill, Glasgow G3 8S.

1 Cardiac catheterisation and angiocardiography. In: Anderson RH, Macartmey FJ, Shinebourne EA, Tynan M, Paediatric cardiology. Edinburgh, London, Melbourne, New York: Churchill Livingstone, 1987:372.

\section{Cardiac catheterisation with 5 French} catheters

SIR,-In his letter commenting on the use of 5F catheters for coronary angiography, $\mathrm{Dr}$ Raphael calls for further randomised studies to compare the latest $5 \mathrm{~F}$ catheters with conventional 7F catheters (British Heart Journal 1991;66:114). He and your readers may be interested to know that such a trial was undertaken in Bristol using the types of $5 \mathrm{~F}$ catheter available in 1988 and $1989 .{ }^{\prime}$ The full results of this trial are due to be published soon in the International Journal of Cardiac Imaging; however, the main message of the trial was that the $5 \mathrm{~F}$ catheters available at that time proved extremely unsatisfactory for coronary angiography and could not be recommended for routine use. Catheter design has progressed rapidly, or at least so we are told by the catheter manufacturers. It may be that the time is now right for a further randomised study to compare the current generation of $5 \mathrm{~F}$ catheters with conventional catheters. Such a study will need to include not only subjective assessments of catheter performance but will also need to document objective measures of catheter performance such as procedure time, injection pressures, and incidence of significant complications.

GEORGE G HARTNELI

Department of Radiology New England Deaconess Hospital, 185 Pilgrim Road,
Boston, Massachusetts 02215, USA

1 Brown E, Morris K, Wild RPH, Hartnell GG Limitations in the performance of 5-F coronary catheters in routine angiography [abstract]. Clin Radiol 1989;40:648.

Genesis of Still's innocent systolic murmur

SIR,-The recent publication of the paper on Still's innocent systolic murmur ${ }^{1}$ prompted queries about who Still was and whether Still's disease commemorates the same individual.

George Frederic Still was indeed the author of early descriptions of both conditions. His personal history has been elegantly described by Hamilton. ${ }^{2}$ Still was educated a Caius College, Cambridge, qualified in medicine at Guy's Hospital in 1893 and, after posts at the Hospital for Sick Children, Great Ormond Street, was appointed to the first chair of paediatrics in London, at King's College Hospital, in 1906. His publications included five books and 108 papers, ${ }^{3}$ among the earliest being his classic description of the form of chronic arthritis in childhood that bears his name.

In his book Common Disorders and Diseases of Childhood the innocent systolic murmur is referred to as a "physiological bruit" which must be differentiated from the "sometimes musical character of murmurs occurring in bacterial endocarditis". He describes the innocent murmur in these terms: "It is heard usually just below the level of the nipple, and about half way between the left margin of the sternum and the vertical nipple line; it is no heard in the axilla nor behind; it is systolic and is often so small that only a careful observer would detect it; moreover, it is ver variable in audibility...; its characteristic feature is a twanging sound, very like that made by twanging a piece of tense string" This description remains accurate and authoritative to this day.

HYAM S JOFFE Cardiology Department Bristol Royal Children's Hospital, St Michael's Hill,
Bristol BS2 8BJ

1 Gardiner HM, Joffe HS. Genesis of Still's murmurs: a controlled Doppler echocarmurmurs: a controlled Doppler echocar-

2 Hamilton EBD. George Frederic Still. Ann Rheum Dis 1986;45:1-5.

3 Franklin AW. A handlist of the writings of George Frederic Still. Arch Dis Child 1941, 16:154-5.

4 Still GF. On a form of chronic joint disease in children. Med-Chir Trans 1897;80:47-59.

5 Still GF. Common disorders and diseases of childhood. 3rd ed. London: Oxford University Press, 1920:495.

\section{Is cardiac rehabilitation necessary?}

SIR,-Precise identification of the specific needs of individual coronary patients for rehabilitative care and precise recommendations regarding the components of this care will enable precise assessment of the outcomes of these interventions.

The occurrence of a coronary event and/or 